Editorial

\title{
Workshop: Hacking Societies, Habits and Rituals, Berkeley $2019^{\dagger}$
}

\author{
Raffaela Giovagnoli * and Gianfranco Basti * \\ Pontifical Lateran University, Vatican City, 00120 Rome, Italy \\ * Correspondence: giovagnoli@pul.it (R.G.); basti@pul.va (G.B.) \\ + Workshop Hacking Societies, Habits and Rituals, Berkeley, CA, USA, 2-6 June 2019. \\ Published: 7 May 2020
}

Abstract: We introduce the workshop "Hacking Societies, Habits and Rituals" to show some important contributions on the topic and aim at stimulating further discussion.

Keywords: habits; rituals; information; we-intentionality

\section{Introduction}

The workshop "Hacking Societies, Habits and Rituals" is inspired by the interesting discussion that took place at the IS4SI Summit 2017 (Gothenburg) and IS4SI Summit 2019 (Berkeley). The traditional sense of habit (habitus) was introduced by Aristotle to characterize the notion of "virtue". Virtue is a habit as disposition to face good or bad emotions and tendencies. Aquinas inherited the Aristotelian view and maintains that habit is not potency (i.e., a capacity) in that it makes us able or unable to do good or wrong. This notion of habit is defined also by Dewey, who thinks that it is a human activity that is influenced by previous activity, namely it is acquired. It includes a certain order and a certain system of minor elements of action. It is a dynamic disposition that is operative in a subordinate form even when it is not the dominant activity at a certain time (Human Nature and Conduct 1921). The meaning of the term habit (consuetudo) is the constant repetition of an event or a behavior, due to a mechanism that can be physical, psychological, biological, social etc. Standardly, it is assumed that this mechanism mostly develops from the repetition of acts and behaviors, and so, in the case of human events, through training. Aristotle, conceived habit as a species of mechanism that is analogous to natural mechanisms, and somehow guarantees the uniform repetition of facts, acts, or behavior by eliminating or reducing effort and fatigue.

Habits and rituals play a fundamental role in human life and are worthy to be considered also because they represent a form of embodied knowledge. They have been studied mostly by disciplines like anthropology, sociology and psychology. Philosophy as well offers interesting analyses from different perspectives, from Aristotle to Bourdieu. Aristotle represents a fundamental perspective to investigate the dimensions entailed by the notion of habit, while Peircean habits connect to the life of symbols and express our relationship with environment through a special kind of "manipulative abduction" (Magnani). Habits are at the center of the Peircean reflection on science and religion. Peirce is like Popper, a fallibilist opposing the logical positivist epistemology of verification of scientific theories and models (Brier). The end of research is an ideal far away in the future. He is not a mechanist but a process philosopher, meaning that his ontology remains open. Peirce thinks that the spiritual and religious worldview should be of the same fallibilist nature and that they in this way could and should support each other's development. Peirce sees, through his triadic semiotics, the universe as a very abstract symbolic process in self-development, unfolding its laws in the process. It is a very anti-fundamentalist view, avoiding any kind of scientism and fundamentalist religion. It sees the formation of habit in thirdness taking as the basic process of our reality in nature, experience, cognition and communication. Habit taking is of course also basic to all kinds of magic and religious 
rituals, but people often forget that they are habits and not universal laws, and therefore will undergo progressive change. Very interesting researchers investigate the relationship between habits, code and learning in biosemiotics (Deacon). Habermas' thought has been devoted to religion since his earlier works about critical theory and the rationalization of society. I think that, because of the original theory of rationalization through the medium of communication, it is important to consider both "ordinary" and "extra-ordinary" aspects so that religious practices are not undetermined. This is an option that connotes Habermas' last thought. Rituals are an important component of human social life and show the failure of secularization's process. What does "post-secular" mean? The sociologist José Casanova introduced this notion, and the discussion on the role of rituals in contemporary society is relevant.

Of all human belief systems and practices, religions are the most strongly connected to habits and rituals in the form of prayers, meditations, sacrifices, sermons, services, trances, initiation rites and more. Habits and rituals offer a common ground that can help to stimulate the discussion from different scientific and cultural perspectives. Recall the anthropological studies of Ernesto De Martino, he stressed that the experience of the precariousness of human life (rather than natural events and therefore stereotyped behaviors) offers reassuring models to follow by building the same tradition. The sociologist Emile Durkheim analyzed the transition from the initial part of the rite to a social function which strengthens the internal community ties; so also did the functionalist anthropologist Bronislaw Malinowski. Instead anthropologists Arnold Van Gennep and Meyer Fortes considered the primary social and cultural role of the myth that can extend later in the religious sphere. Fundamental, important psychoanalysis showed the presence of an unconscious ritual in most everyday human behaviors. The personalities of obsessive-compulsives are subject to the expression of personal rituals; a typical case of our day is to verify that you have closed the gas when leaving the house or have closed the door and the machine; very common is walking without stepping on the lines. The ritual is the personal dimension and social needs of a deep emotional involvement, without which it ceases to exist. The ritual requires a different aesthetic component in different cultures and in different times; the rite must evolve to not lose meaning. For example, in the religious sphere of Christianity, while for the Western Catholic community organ sound is perceived as powerful and becomes the "divine" instrument, for the Eastern Christianity community it the sound of the organ is perceived as cacophony and away from the concept of the sacred.

Modern studies point attention to the dynamic of the ritual. For example, Roy Rappaport studied the cyber dimension of the ritual and the ritual implications for ecology and communication. Religious rites such as bullfighting are experienced by the participants with passion but arouse horror for animal welfare. More positively, rock concerts or the mega-rallies take the outline of a ritual and are experienced with a strong emotional involvement. The contribution of important philosophers like Searle and Habermas enrich the investigations on rituals and stimulates the discussion on the source of them. Generally speaking, they point to the basic function of rituals, from the simple expressions of non-human animals to the complex structure of human language. The main point is communication which serves to inform others about events in the world, sharing basic emotions and solving problems. From this simple structure rituals in human life appear to facilitate important passages both biological and social, and to share and elaborate emotions related to them. Human rituals require symbolization that can be represented in different forms. The attribution of a symbolic value to certain objects, animals and procedures. The object acquires a status function and counts as something that is recognized to mean something else. For instance, the ceremony to award diplomas requires students to dress in robes which means the passage to a higher level of education and the potential access to a prestigious university. In bullfights, people assign a symbolic value to the bull and to the peculiar uniform of the toreador. In this case, to kill a bull is not considered a good practice in every culture (like eating lamb for Easter). On the contrary, to acquire a higher level of education can be universally considered a good practice. It seems that language (written or spoken) is a component that is not always present in rituals. Let's think to dance as a performance largely present in rituals. Differently, in the tea ceremony the ritual focuses on a codified set of sentences as well as on 
some specific objects used to prepare the tea, so that they acquire a certain value in the meaning of the very ritual.

We present interesting contributions that are related to contemporary trans-disciplinary and trans-cultural debates:

1. The nature and role of habits in natural and social sciences

2. Ethical issues of habits and AI, for example the implication of the introduction of robotics and intelligent agents in different contexts

3. The nature and role of rituals in multicultural societies

4. Ethical issues of habits and rituals and their relevance for human life

5. The relationship between habits and rituals as continuity or discontinuity between personal and social context introduction should briefly place the study in a broad context and define the purpose of the work and its significance.

Funding: This research received no external funding.

Acknowledgments: We would like to thank Terrence Deacon, who organized a wonderful summit at UCB. We also thank all the participants to our workshop for their very interesting contributions, that stimulated a lively discussion.

Conflicts of Interest: The authors declare no conflict of interest.

(C) 2020 by the authors. Licensee MDPI, Basel, Switzerland. This article is an open access article distributed under the terms and conditions of the Creative Commons Attribution (CC BY) license (http://creativecommons.org/licenses/by/4.0/). 